\title{
Uma Metodologia para Comparação entre Modelos de Elementos Finitos COM APLICAÇÃo Na SimULAÇão DinÂMICA DE IMPLEMENTOS RODOVIÁRIOS
}

\author{
Julian Marcell Enzveiler Marques ${ }^{1.2}$, Rogério José Marczak ${ }^{1}$ \\ ${ }^{1}$ Universidade Federal do Rio Grande do Sul \\ ${ }^{2}$ Ciber Equipamentos Rodoviários Ltda. \\ E-mails: julian.marcell@ufrgs.br, rato@mecanica.ufrgs.br
}

\section{RESUMO}

Modelos numéricos distintos para um mesmo problema são empregados na indústria por variadas razões. Isto é, é comum se empregar um modelo de elementos finitos (EF) de placa ou sólido para realizar análise de tensões e um modelo de vigas para as simulações dinâmicas. Assim, é de interesse tecnológico e industrial que se empregue um mesmo modelo numérico. Com esse intuito, o presente trabalho propõe uma metodologia capaz de comparar diferentes modelos de EF de um mesmo equipamento, visando a seleção de um único para todas as análises. A metodologia leva em conta os diferentes elementos finitos empregados, as simplificações inerentes aos modelos estruturais usados, e potenciais restrições cinemáticas aplicadas ao modelo. A comparação é feita através de ferramentas comerciais que executam as análises modal e harmônica, mapeando as diferentes malhas a um esqueleto nodal e os resultados comparados para índice MAC e erro nas frequências naturais. Assim, o analista pode selecionar malhas com quantidade viável de graus de liberdade, sem comprometer significativamente os resultados, e tornar possível simulações dinâmicas transientes que seriam impraticáveis com modelos muito detalhados.

\section{INTRODUÇÃO}

Atualmente, o emprego de modelos numéricos nas análises em elementos finitos (EF) prevê o desempenho e confiabilidade de estruturas cada vez mais complexas na indústria. Por outro lado, em diversas situações, tal previsão é difícil, pois inúmeros parâmetros são relevantes e comprometem consideravelmente os resultados. Para problemas de engenharia os seguintes pontos são fundamentais: seleção do modelo discreto de corpos rígidos para o caso de implementos rodoviários, hipóteses simplificadoras que possam ser usados em problemas dinâmicos e determinação das forças e vinculações na estrutura. Diante desses desafios, o uso do correto modelo de elementos finitos (EF) permite analisar tensões e prever a vida em fadiga das estruturas com menor custo computacional.

Assim sendo, o objetivo desse trabalho é apresentar uma metodologia capaz de comparar elementos de placa e viga com diferentes condições de contorno e encontrar um único para futuras simulações dinâmicas. Os estudos são baseados no método de elementos finitos (MEF) devido a aplicação nas diversas áreas da indústria, muito difundido na área acadêmica e o mais indicado para analises modais e harmônicas de geometrias com alto grau de detalhamento. 
O trabalho que está sendo proposto, vem ao encontro da necessidade do analista realizar analises dinâmicas transiente de implementos rodoviários. No entanto, convém ressaltar que analises de estruturas submetidas a solicitações oscilatórias podem utilizar a presente metodologia.

Os resultados são comparados utilizando ferramentas comerciais que auxiliam na obtenção aproximada da solução do problema. Além das análises modais e harmônicas obtidas como solução do problema, aplica-se uma das principais técnicas de comparação dos modos de vibração, índice de MAC, que quantifica o grau de similaridade entre dois vetores.

\section{FORMULAÇÃO MATEMÁTICA}

Os modelos matemáticos que analisam o comportamento dinâmico de estruturas complexas com vários graus de liberdade são discretizados e representado por matrizes. Geralmente isso é feito através de EF como nesse estudo. Desta forma, o problema dinâmico parte da equação do movimento que representa um sistema de várias equações diferenciais de segunda ordem.

$$
M \ddot{\mathbf{q}}(t)+C \dot{\mathbf{q}}(t)+K \mathbf{q}(t)=\mathbf{f}(t)
$$

As matrizes $M, C$ e $K$, consistem, respectivamente, a matriz de massas, amortecimento e rigidez, cujos elementos $M_{i j}, C_{i j}$ e $K_{i j}$ representam as forças que incidem no grau de liberdade $\mathrm{i}$, quando no grau de liberdade $\mathrm{j}$ é imposta uma aceleração, uma velocidade ou um deslocamento. Por sua vez os vetores $\ddot{\mathbf{q}}(t), \dot{\mathbf{q}}(t)$ e $\mathbf{q}(t)$ contêm as acelerações, velocidades e deslocamentos generalizados relativos a cada um dos graus de liberdade da estrutura, enquanto o vetor $\mathbf{f}(t)$ contém as forças aplicadas em cada um dos graus de liberdade, Equação (1).

O estudo para determinação das equações que regem o problema segue com a análise modal e Função Resposta em Frequência a partir da equação do movimento de sistemas com vários graus de liberdade.

\subsection{Analise modal de um sistema sem amortecimento}

A formulação modal pode ser resolvida apoiado no método da superposição modal. Tal método tem sua aplicação em sistemas lineares, no qual consiste na mudança de base que passa das coordenadas nodais às coordenadas generalizadas. Assim, as equações tornam-se desacopladas, o que possibilita que as suas resoluções sejam feitas de forma independente e com resposta a partir da superposição das respostas de cada equação.

Parte-se da equação de movimento de sistemas com vários graus de liberdade não amortecidos:

$$
M \ddot{\mathbf{q}}(t)+K \mathbf{q}(t)=\mathbf{0}
$$

Ao resolver a equação diferencial ordinária linear de segunda ordem, Equação (2), e realizar algumas operações algébricas, chega-se à:

$$
-\omega^{2} M \mathbf{c}+K \mathbf{c}=\mathbf{0}
$$


onde c é o vetor da constante da integral da solução do problema e $\omega$ é a frequência natural. Observa-se que a Equação (3) é classificado como um autoproblema. A descrição de métodos para a solução do autoproblema não será aqui vista em detalhes, pois pode ser facilmente encontrada na literatura. O determinante do sistema é da forma:

$$
\operatorname{det}(\lambda I-D)=\mathbf{0}
$$

Lembrando que na Equação (4), $D$ é a matriz dinâmica e $I$ matriz identidade. Desta forma, o autovalor será associado ao autovetor encontrado, ou seja, para cada frequência natural $\lambda=\omega^{2}$ existe um vetor $\mathbf{c}$. Também, convêm ressaltar que os modos de vibração são organizados de forma que o primeiro modo seja a primeira coluna da matriz e o segundo modo a segunda coluna da matriz e assim por diante. Portanto,

$$
\mathbf{f} \Phi=\left[\begin{array}{c}
\omega_{1} \\
\omega_{2} \\
\vdots \\
\omega_{n}
\end{array}\right]\left[\begin{array}{llll}
\mathbf{c}_{1} & \mathbf{c}_{2} & \ldots & \mathbf{c}_{n}
\end{array}\right]
$$

onde f é o vetor com as frequências naturais e $\Phi$ é a matriz dos modos de vibração.

A Equação (5) mostra os modos e as frequências, mas para encontrar um novo sistema de coordenadas, na qual as equações estejam desacopladas é necessário introduzir a forma:

$$
\mathbf{q}(t)=\Phi \mathbf{r}(t)
$$

a qual $\mathbf{r}(t)$, Equação (6), representa o vetor de participação associado aos modos de vibração da estrutura, ou seja, vetor que realiza a mudança de variável. Logo, a equação do movimento de um sistema de vários graus de liberdade sem amortecimento fica:

$$
M \Phi \ddot{\mathbf{r}}(t)+K \Phi \mathbf{r}(t)=\mathbf{0}
$$

A Equação (7) é facilmente resolvida multiplicando por $\Phi^{T}$ e utilizando as relações de ortonormalidade, propriedade de autovalor e autovetor. Assim, chega-se à:

$$
\Phi^{T} M \Phi \ddot{\mathbf{r}}(t)+\Phi^{T} K \Phi \mathbf{r}(t)=\mathbf{0}
$$

Conhecendo as propriedades matemáticas de independência linear e álgebra, a partir da Equação (8) obtêm-se:

$$
\begin{gathered}
\Phi^{T} M \Phi=I \\
\Phi^{T} K \Phi=\Lambda=\operatorname{diag}\left[\omega_{1}^{2} \omega_{2}^{2} \ldots \omega_{n}^{2}\right]
\end{gathered}
$$


onde $\Lambda$ é a matriz diagonal dos autovalores ou frequências naturais, Equação (9) e Equação (10).

Finalmente, o resultado é um sistema de equações diferenciais não homogêneo sendo possível resolvê-lo como se cada equação correspondesse a um grau de liberdade:

$$
\ddot{\mathbf{r}}_{i}(t)+\omega_{i}^{2} \mathbf{r}_{i}(t)=\mathbf{0}, i=1,2, \ldots, n
$$

em que $n$ corresponde ao número de graus de liberdade considerado, Equação (11).

\subsection{Função Resposta em Frequência}

A equação do movimento de um sistema com vários graus de liberdade amortecido pode ser resolvido e escrito em coordenadas modais. Da mesma forma que anteriormente, é necessário assumir a ortogonalidade dos modos de vibração em relação a matriz de amortecimento. Sendo assim, equação do movimento desacoplada com amortecimento é expressa por:

$$
\ddot{\mathbf{r}}_{i}(t)+2 \xi_{i} \omega_{i} \dot{\mathbf{r}}_{i}(t)+\omega_{i}^{2} \mathbf{r}_{i}(t)=\mathbf{p}(t), i=1,2, \ldots, n
$$

onde $\xi_{i}$ é a razão de amortecimento do sistema.

Considerando uma excitação harmônica a resposta do sistema linear será também harmônica e com a mesma frequência de excitação. Chama-se de Teorema da Preservação da Frequência:

$$
\mathbf{p}(t)=\mathbf{p}_{0} \cos \omega t+\mathbf{p}_{0} \cos \omega t
$$

sendo $\mathbf{p}_{\mathbf{0}}$ a amplitude da força excitadora, Equação (13).

A Equação (12) pode ser resolvida no domínio do tempo através do integral de Duhamel ou ser transformada para o domínio da frequência, recorrendo à transformada de Fourier, Equação (14).

$$
\mathbf{r}_{i}(\omega)=\int_{-\infty}^{\infty} \mathbf{r}_{i}(t) e^{-i \omega t} d t
$$

Então, a primeira derivada de $\mathbf{r}_{i}(\omega)$ é:

$$
\dot{\mathbf{r}}_{i}(\omega)=-\mathbf{r}_{i}(0)+i \omega \mathbf{r}_{i}(\omega)
$$

A segunda derivada é calculada de acordo:

$$
\ddot{\mathbf{r}}_{i}(\omega)=-\dot{\mathbf{r}}_{i}(0)+i \omega \mathbf{r}_{i}(0)-\omega^{2} \mathbf{r}_{i}(\omega)
$$


Fazendo as substituições necessárias através da Equação (15) e Equação (16) o resultado no domínio da frequência é definido de acordo com:

$$
\begin{gathered}
-\omega^{2} \mathbf{r}_{i}(\omega)+i 2 \xi_{i} \omega \omega_{i} \mathbf{r}_{i}(\omega)+\omega_{i}^{2} \mathbf{r}_{i}(\omega)=\mathbf{p}_{i}(\omega) \\
\mathbf{r}_{i}(\omega)=\frac{1}{-\omega^{2}+i 2 \xi_{i} \omega \omega_{i}+\omega_{i}^{2}} \mathbf{p}_{i}(\omega)
\end{gathered}
$$

A Equação (17) e Equação (18) também podem ser representadas da seguinte maneira:

$$
\mathbf{r}_{i}(\omega)=H_{i}(\omega) \mathbf{p}_{i}(\omega)
$$

Logo, a Função Resposta em Frequência é dado por:

$$
H_{i}(\omega)=\frac{1}{-\omega^{2}+i 2 \xi_{i} \omega \omega_{i}+\omega_{i}^{2}}
$$

Assim sendo, a Equação (19) relaciona o vetor de excitação $\mathbf{p}_{i}(\omega)$ e a Função Resposta em Frequência $H_{i}(\omega)$, Equação (20).

\section{3. Índice MAC Modal Assurance Criterion}

Os índices MAC é uma técnica largamente utilizada para estimar um grau de correlação de dados em formas modais. Os vetores modais de uma análise de elementos finitos podem ser comparadas com valores determinados experimentalmente, bem como vetores modais determinados por meios de diferentes métodos. Nesta abordagem, os métodos podem ser comparados de forma a avaliar a consistência entre eles [1].

São elaboradas duas matrizes com os valores obtidos pelas análises modais A primeira matriz é referente a analise modal com um tipo de EF e a segunda com outro tipo de EF. O índice de MAC pode ser calculado como:

$$
M A C_{j k}=\frac{\left|\emptyset_{m j}^{T} \emptyset_{a k}\right|^{2}}{\left(\emptyset_{a k}^{T} \emptyset_{a k}\right)\left(\emptyset_{m j}^{T} \emptyset_{m j}\right)}
$$

onde $\emptyset_{m j}$ é a matriz dos deslocamentos obtidos na primeira análise de modal de EF e $\emptyset_{a k}$ matriz dos deslocamentos obtidos pela segunda analise modal de EF.

Esse cálculo, Equação (21), é realizado para cada posição da matriz do índice de MAC. Valores próximos a unidade indicam que o modelo está convergindo, ou seja, relacionados.

\section{METODOLOGIA}

O desenvolvimento de uma metodologia capaz de comparar diferentes modelos de EF e selecionar o correto para todo e qualquer analise dinâmica compreende basicamente duas etapas. A primeira etapa discute um caso simples de uma viga em balanço afim de validar, 
posteriormente, a estrutura chassi de um implemento rodoviário. A segunda apresenta, descreve e discute a estrutura chassi proposta. Ambos os casos utilizam ferramentais comerciais para determinar os modos de vibração, frequências naturais, Função Resposta em Frequência e o índice de MAC da estrutura.

Para fins de estudos o material empregado em todas as análises desse trabalho tem comportamento elástico linear, é um material isotrópico com pequenos deslocamentos. A Tabela 1 mostra as propriedades mecânicas do aço estrutural.

Tabela 1 - Propriedades mecânicas aço estrutural.

\begin{tabular}{|l|c|}
\hline Tensão de escoamento & $2,5 \mathrm{E}+3 \mathrm{MPa}$ \\
\hline Tensão de ruptura & $4,6 \mathrm{E}+3 \mathrm{MPa}$ \\
\hline Modulo de elasticidade & $2,0 \mathrm{E}+5 \mathrm{MPa}$ \\
\hline Coeficiente de Poisson & 0,3 \\
\hline
\end{tabular}

2.1. Modelo simples de uma viga em balanço

O modelo mais simples, de uma viga em balanço é discutido para facilitar a compreensão e validar a estrutura chassi do implemento rodoviário. Esse modelo é dividido em duas teorias estruturais clássicas: teoria de viga de Timoshenko e as hipóteses de Mindlin-Reissner para placas.

A primeira discretização do modelo é feita com elementos de placa que é apropriado para analisar chapas finas de estruturas. Placas são compostas por duas dimensões cartesianas comparáveis e outra com ordem de grandeza inferior, ou seja, uma placa semi-espessa que pode ser considerada apenas por seu plano médio. Conforme Ansys [2], elemento de placa ou SHELL281 tem 8 nós com 6 graus de liberdade cada: translação e rotação no eixos $\mathrm{X}, \mathrm{Y}$ e Z .

A Figura 1 (a) ilustra a malha em EF da viga em balanço simples com elementos de placa. Considerando tamanho do elemento de $25 \mathrm{~mm}$ por $25 \mathrm{~mm}$ e dimensões da viga em balanço de $100 \mathrm{~mm}$ largura por $500 \mathrm{~mm}$ comprimento, tem-se 80 elementos, 289 nós e 1680 graus de liberdade.

A segunda malha, Figura 1 (b), para a mesma viga em balanço é empregado elementos de viga. O elemento de viga ou BEAM189 é um elemento de barra tridimensional, sendo adequado para a análise de estruturas que possuem espessuras, como por exemplo vigas finas e relativamente grossas. Considera os efeitos de deformação de cisalhamento ou por esforço cortante, pois se baseia na teoria de viga de Timoshenko. Trata-se de um elemento de viga quadrático com três nós possuindo seis graus de liberdade em cada nó [2]. 

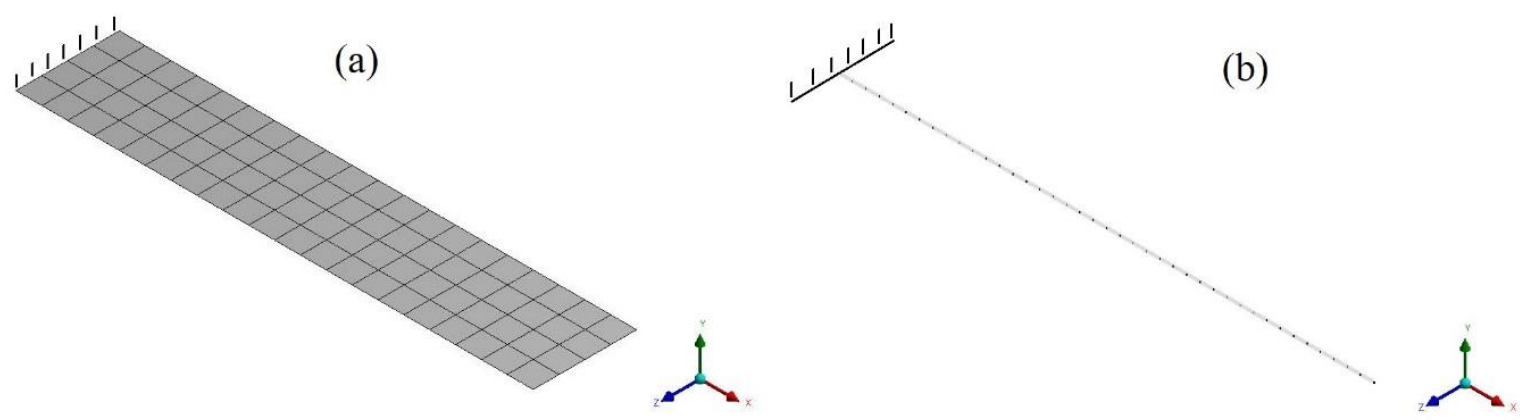

Figura 1 - Malha do caso simples com elementos de placa e viga.

Por último, obtêm-se 20 elementos, 61 nós e 240 graus de liberdade aplicando elementos de viga para a viga em balanço.

As condições de contorno para esse modelo são iguais para os dois tipos de elementos finitos, placa e viga. Dessa maneira, a excitação para analise harmônica é $1 \mathrm{~g}$ vertical, direção de Y, e $1 \mathrm{~g}$ horizontal, direção de Z.

\subsection{Estrutura chassi de um implemento rodoviário}

A simulação de implementos rodoviários é um trabalho muito complexo, pois abrange a utilização de modelos em dinâmica. Gillespie [3] refere em um de seus trabalhos essa importância: "A existência do modelo fornece um meio para identificar os fatores importantes, o modo que eles operam e sob quais condições. O modelo fornece também uma capacidade de predição, de forma que as mudanças necessárias para se atingir uma determinada meta de desempenho possam ser identificadas".

Vargas [4] descreve na sua dissertação os processos de modelagem de um veículo. Citase dois desses importantes processos:

- $\quad$ A escolha dos corpos rígidos a serem representados e as vinculações entre eles. Ambos são dependentes do tipo do veículo e de estudo que se pretende realizar.

- A suspensão tem grande importância, definindo o desempenho dinâmico e vibracional do veículo. Além dos elementos clássicos deste sistema, como molas e amortecedores, o pneu tem essencial participação no comportamento do modelo.

O implemento rodoviário analisado nesse trabalho trata-se de uma usina de asfalto do tipo móvel, Figura 2. O cavalo mecânico não é considerado nas simulações dinâmicas. A Tabela 2 apresenta as características gerais do implemento rodoviário.

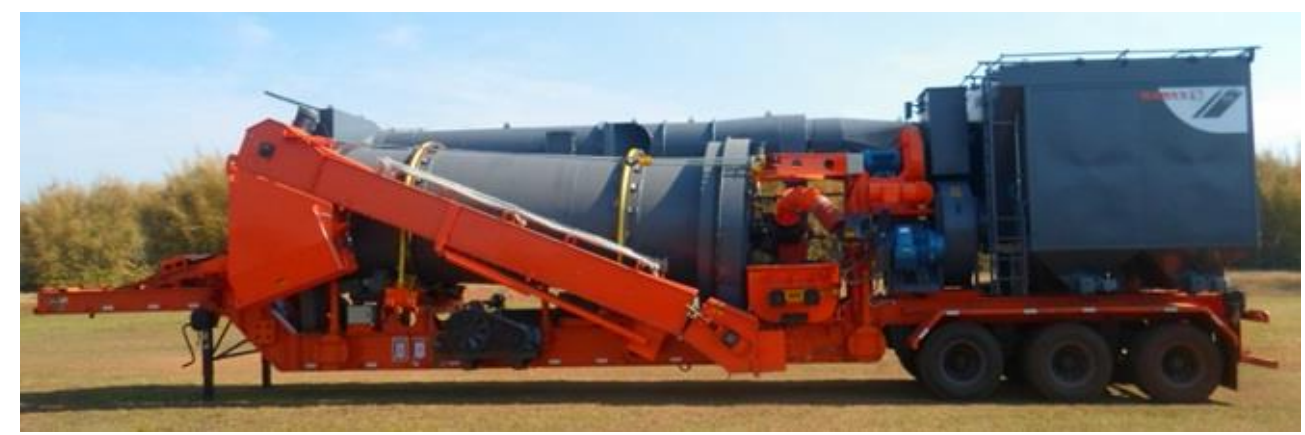

Figura 2 - Implemento rodoviário utilizado nas análises. 
Tabela 2 - Características gerais do implemento rodoviário.

\begin{tabular}{|l|c|}
\hline Peso bruto total - PBT & $33800 \mathrm{~kg}$ \\
\hline Comprimento & $17165 \mathrm{~mm}$ \\
\hline Largura & $3200 \mathrm{~mm}$ \\
\hline Altura & $4400 \mathrm{~mm}$ \\
\hline
\end{tabular}

Os valores de massa de cada subsistema são os principais dados de entrada para as simulações numéricas, Tabela 3. Diferente de outras combinações veiculares de carga, o carregamento é sempre o mesmo.

Tabela 3 - Massa de cada subsistema.

\begin{tabular}{|l|c|}
\hline Secador Rotativo Contra Fluxo e Roletes de Apoio & $7300 \mathrm{~kg}$ \\
\hline Queimador e Câmara de Combustão & $800 \mathrm{~kg}$ \\
\hline Misturador e Sistema de Injeção de Asfalto & $2500 \mathrm{~kg}$ \\
\hline Filtro de Mangas e Caracóis & $3100 \mathrm{~kg}$ \\
\hline Exaustor e Soprador & $1500 \mathrm{~kg}$ \\
\hline Elevador de Arraste & $3200 \mathrm{~kg}$ \\
\hline Tubulação de Gases & $1200 \mathrm{~kg}$ \\
\hline Silo Dosador & $1800 \mathrm{~kg}$ \\
\hline Câmara de Aspiração & $750 \mathrm{~kg}$ \\
\hline Rodado 1 & $1200 \mathrm{~kg}$ \\
\hline Rodado 2 & $1200 \mathrm{~kg}$ \\
\hline Rodado 3 & $1200 \mathrm{~kg}$ \\
\hline Chassi sem Rodados & $8050 \mathrm{~kg}$ \\
\hline
\end{tabular}

Seguindo a utilização de 2 tipos de EF empregados no caso simples de uma viga em balanço, o caso da estrutura chassi do implemento rodoviário é discretizado com elementos de placa e viga.

A Figura 3 (a) mostra a estrutura do chassi com a malha composta por elementos de alta ordem, placa. Por sua vez, a Figura 3 (b) ilustra a malha do chassi com elementos de viga.
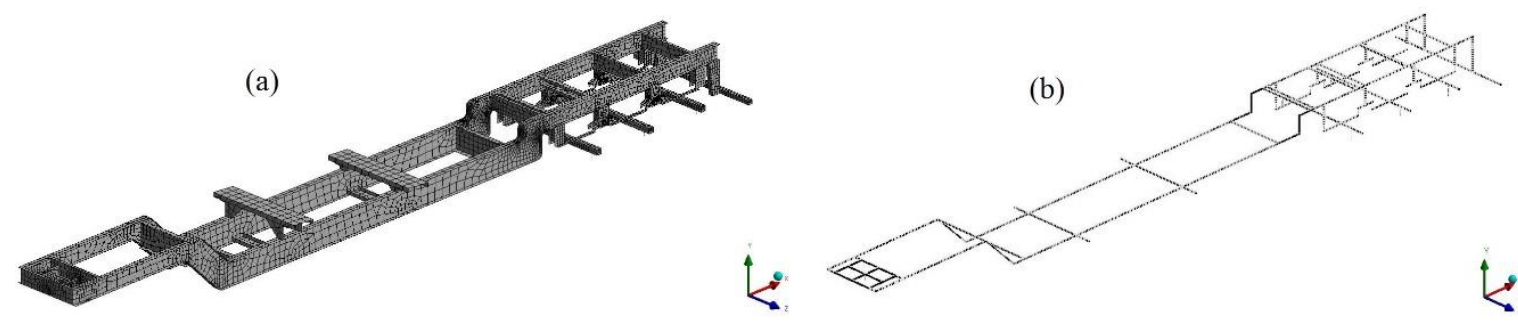

Figura 3 - Malha da estrutura chassi com elementos de placa e viga.

A estrutura chassi é simulada pelo MEF com 3 casos diferentes de vinculações e uniões dos corpos. A primeira o modelo conta com elementos de mola representando os pneus e feixes de mola trapezoidal da suspensão tandem. O modelo também tem restrição de translação em X, Y e Z na base, Figura 4 (a). 
O elemento de mola ou COMBIN14 é um elemento de tração e compressão uniaxial com 3 graus de liberdade em cada nó: translação nos eixos X, Y e Z. A rigidez ou amortecimento pode ser removido do elemento e não possui massa associado [2].

O segundo modelo possui elementos rígidos unindo suspensão e estrutura chassi, sem elementos de molas para os pneus e apoio simples restringindo translação X, Y e Z, Figura 4 (b).

Já o último conta com elementos rígidos unindo suspensão e estrutura chassi, sem elementos de molas para os pneus e sem apoios, ou seja, vibração livre, Figura 4 (c).

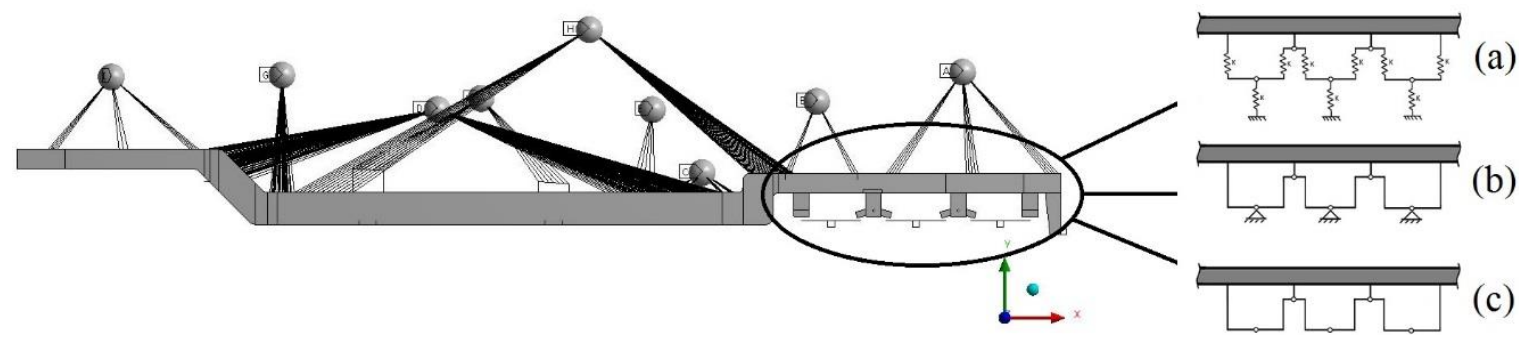

Figura 4 - Condições de contorno da estrutura chassi.

Hoje a forma comum de encontrar os deslocamentos globais, modos e frequências naturais, da estrutura chassi é através da vibração livre, isto é, de acordo com o último caso descrito. Além do mais, os primeiros 6 modos de vibração livre da estrutura são descartados por representar contribuições negligentes as respostas dinâmicas do sistema [5].

Por fim, a quantidade de elementos, nós e graus de liberdade de cada caso da estrutura chassi pode ser vista na Tabela 4.

Tabela 4 - Quantidade de elementos, nó e graus de liberdade de cada modelo.

\begin{tabular}{|l|c|c|c|c|c|c|}
\cline { 2 - 7 } & \multicolumn{3}{c|}{ Modelo com elementos de } & \multicolumn{3}{c|}{ Modelo com elementos de } \\
placa & \multicolumn{3}{c|}{ viga } \\
\cline { 2 - 7 } & $\begin{array}{c}1^{\circ} \\
\text { Modelo }\end{array}$ & $\begin{array}{c}2^{\circ} \\
\text { Modelo }\end{array}$ & $\begin{array}{c}3^{\circ} \\
\text { Modelo }\end{array}$ & $\begin{array}{c}1^{\circ} \\
\text { Modelo }\end{array}$ & $\begin{array}{c}2^{\circ} \\
\text { Modelo }\end{array}$ & $3^{\circ}$ \\
Modelo \\
\hline Elementos & 11233 & 11099 & 11099 & 1576 & 1451 & 1451 \\
\hline Nós & 31990 & 32014 & 32014 & 3180 & 3210 & 3210 \\
\hline Graus de liberdade & 178192 & 183829 & 184066 & 11407 & 11905 & 12142 \\
\hline
\end{tabular}

Para a análise harmônica é inserido uma aceleração de $1 \mathrm{~g}$ vertical, direção de $\mathrm{Y}$, e $1 \mathrm{~g}$ horizontal, direção de Z, se procede da mesma maneira que o caso simples.

\section{RESULTADOS E DISCUSSÃO}

Os resultados são divididos da mesma forma que a metodologia descrita nesse trabalho. Em primeiro momento, discute-se os resultados do modelo de uma viga em balanço para então validar a estrutura chassi do implemento rodoviário. O objetivo do caso simples é mostrar o método da análise para o analista utilizar em diversos casos da engenharia. Posteriormente, a análise da estrutura chassi serve de apoio para casos reais da indústria como outros tipos de implementos rodoviários. 
3.1. Modelo simples de uma viga em balanço

O chave para determinação de respostas dinâmicas de um sistema discretizado em EF, baseia-se na análise modal. Nesta etapa, a meta é a aquisição dos modos e frequências naturais de vibração da estrutura do caso simples de uma viga em balanço.

Para o modelo simples a análise modal é configurada de forma a calcular os modos em uma faixa de frequências de 0 até $300 \mathrm{~Hz}$, o que corresponde ao dobro da frequência de varredura que será empregada na análise harmônica. Neste intervalo, são calculados 10 modos de vibração, porém relacionados apenas os 6 primeiros modos de vibração, Tabela 5.

Tabela 5 - Relação dos modos de vibração do caso simples de uma viga em balanço.

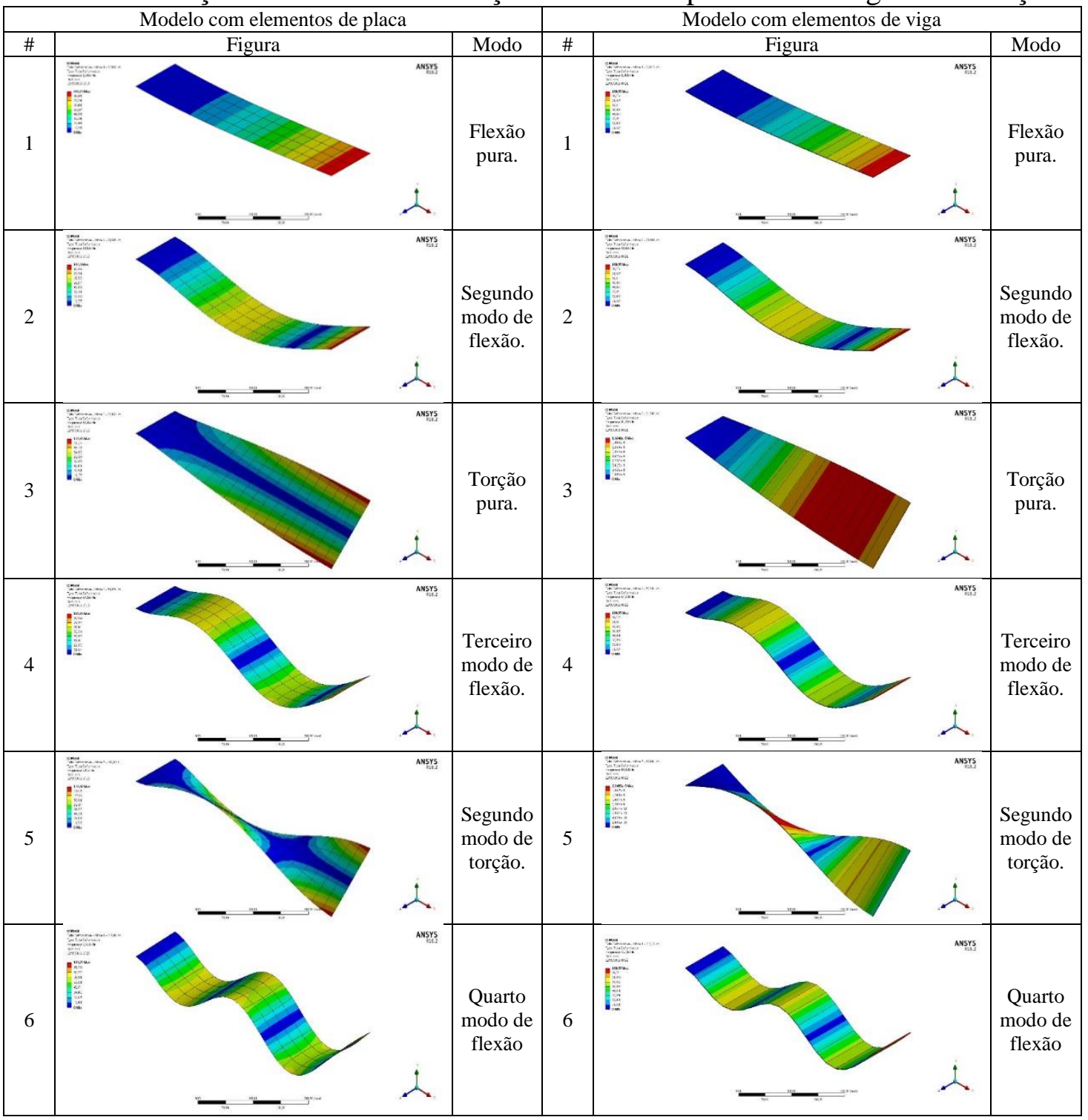

Esses modos se originam de graus de liberdade de deslocamentos translacionais, e, por isso, representam formas reais que a viga em balanço vibra. A comparação dos valores de frequências naturais entre EF do tipo placa e viga para o caso simples de uma viga em balanço estão na Tabela 6 . 
Tabela 6 - Comparação das frequências naturais do caso simples de uma viga em balanço.

\begin{tabular}{|c|c|c|c|c|c|}
\hline Modo & Frequência (placa) & Modo & Frequência (viga) & Diferença & Erro \% \\
\hline 1 & $3,31 \mathrm{~Hz}$ & 1 & $3,26 \mathrm{~Hz}$ & $-0,04 \mathrm{~Hz}$ & $-1 \%$ \\
\hline 2 & $20,69 \mathrm{~Hz}$ & 2 & $20,44 \mathrm{~Hz}$ & $-0,25 \mathrm{~Hz}$ & $-1 \%$ \\
\hline 3 & $32,95 \mathrm{~Hz}$ & 3 & $31,30 \mathrm{~Hz}$ & $-1,65 \mathrm{~Hz}$ & $-5 \%$ \\
\hline 4 & $58,03 \mathrm{~Hz}$ & 4 & $57,23 \mathrm{~Hz}$ & $-0,79 \mathrm{~Hz}$ & $-1 \%$ \\
\hline 5 & $100,80 \mathrm{~Hz}$ & 5 & $93,89 \mathrm{~Hz}$ & $-6,90 \mathrm{~Hz}$ & $-7 \%$ \\
\hline 6 & $114,09 \mathrm{~Hz}$ & 6 & $112,16 \mathrm{~Hz}$ & $-1,93 \mathrm{~Hz}$ & $-2 \%$ \\
\hline
\end{tabular}

As pequenas diferenças entre o resultado de frequência do modelo com EF do tipo placa e viga é aceitável dada as diferenças entre a tecnologia dos elementos. Pode-se realizar uma comparação razoável entre a diferença da quantidade de graus de liberdade e a diferença entre as frequências. Em percentuais tem $-600 \%$ contra $-7 \%$.

De posse dos modos e frequências de vibração da estrutura, é possível utilizar um comando disponível em ferramentas comercias e analisar o índice de MAC. Assim, compara-se cada modo de vibração através dos deslocamentos dos vetores da solução com placa e viga. Os nós de cada malha são mapeados e combinados. Nessa análise, são combinados 21 nós de cada malha. Aplicando a Equação (21), chega-se à Tabela 7 .

Tabela 7 - Valores do índice de MAC do caso simples de uma viga em balanço.

\begin{tabular}{|c|c|c|c|c|c|c|c|c|c|c|c|}
\hline & \multicolumn{10}{|c|}{ Viga } \\
\hline & & 1 & 2 & 3 & 4 & 5 & 6 & 7 & 8 & 9 & 10 \\
\hline \multirow{10}{*}{$\frac{\mathbb{\mathscr { J }}}{\tilde{\Omega}}$} & 1 & 1,00 & 0,00 & 0,00 & 0,00 & 0,00 & 0,00 & 0,00 & 0,00 & 0,00 & 0,00 \\
\hline & 2 & 0,00 & 1,00 & 0,00 & 0,00 & 0,00 & 0,00 & 0,00 & 0,00 & 0,00 & 0,00 \\
\hline & 3 & 0,00 & 0,00 & 1,00 & 0,00 & 0,00 & 0,00 & 0,00 & 0,00 & 0,00 & 0,00 \\
\hline & 4 & 0,00 & 0,00 & 0,00 & 1,00 & 0,00 & 0,00 & 0,00 & 0,00 & 0,00 & 0,00 \\
\hline & 5 & 0,00 & 0,00 & 0,00 & 0,00 & 0,99 & 0,00 & 0,01 & 0,00 & 0,00 & 0,00 \\
\hline & 6 & 0,00 & 0,00 & 0,00 & 0,00 & 0,00 & 1,00 & 0,00 & 0,00 & 0,00 & 0,00 \\
\hline & 7 & 0,00 & 0,00 & 0,00 & 0,00 & 0,01 & 0,00 & 0,96 & 0,00 & 0,03 & 0,00 \\
\hline & 8 & 0,00 & 0,00 & 0,00 & 0,00 & 0,00 & 0,00 & 0,00 & 1,00 & 0,00 & 0,00 \\
\hline & 9 & 0,00 & 0,00 & 0,00 & 0,00 & 0,00 & 0,00 & 0,02 & 0,00 & 0,93 & 0,00 \\
\hline & 10 & 0,00 & 0,00 & 0,00 & 0,00 & 0,00 & 0,00 & 0,00 & 0,00 & 0,00 & 1,00 \\
\hline
\end{tabular}

Como se pode observar o comportamento é muito similar entre os modos de vibração de ambos os tipos de EF aplicados ao modelo de viga em balanço. Os valores obtidos na comparação utilizando o índice de MAC estão na unidade ou muito próximo disso.

A Função Resposta em Frequência de cada modelo com diferente tipo de EF é encontrada depois de inserir a aceleração na estrutura e resolver o problema pelo método de superposição modal. Sem considerar as amplitudes, pois o interesse está na comparação das frequência organizadas no eixo das abscissas, a Função Resposta em Frequência de cada modelo estão relacionadas na Figura 5. A vista superior refere-se ao modelo de placa e a vista inferior modelo de viga. 


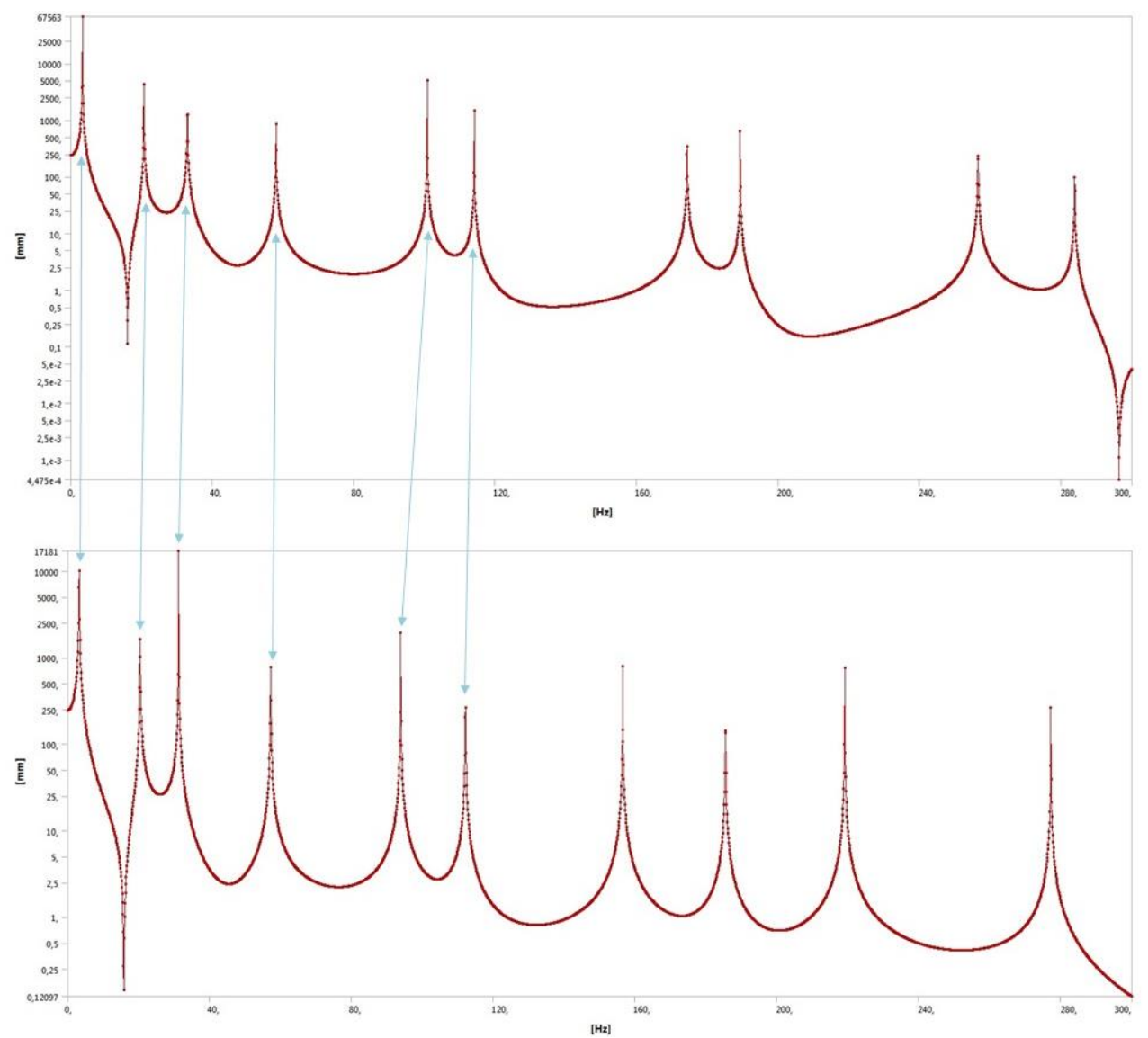

Figura 5 - Função Resposta em Frequência do caso simples de uma viga em balanço.

Nota-se 10 picos na vista superior e inferior da Figura 5 que estão bem relacionados em termos de frequências. As linhas azuis que ligam uma vista a outra mostram a pequena diferença de frequências já discutido anteriormente. Importante lembrar que os modos de torção estão aparecendo na Função Resposta em Frequência devido as acelerações impostas. Com apenas a aceleração de $1 \mathrm{~g}$ vertical não seria possível visualizar os picos dos modos de torção.

\subsection{Estrutura chassi de um implemento rodoviário}

A relação entre os modos de vibração da estrutura chassi com EF de placa e viga é mais difícil que o caso anterior. A geometria não tem mesmo comportamento quando submetida a vibração e sua construção não tem a mesma similaridade. Isso é importante estar claro para as discussões sobre os resultados apresentados.

A Tabela 8 ilustra a relação dos modos de vibração primeiro modelo da estrutura chassi.

Tabela 8 - Relação dos modos de vibração do primeiro modelo da estrutura chassi.

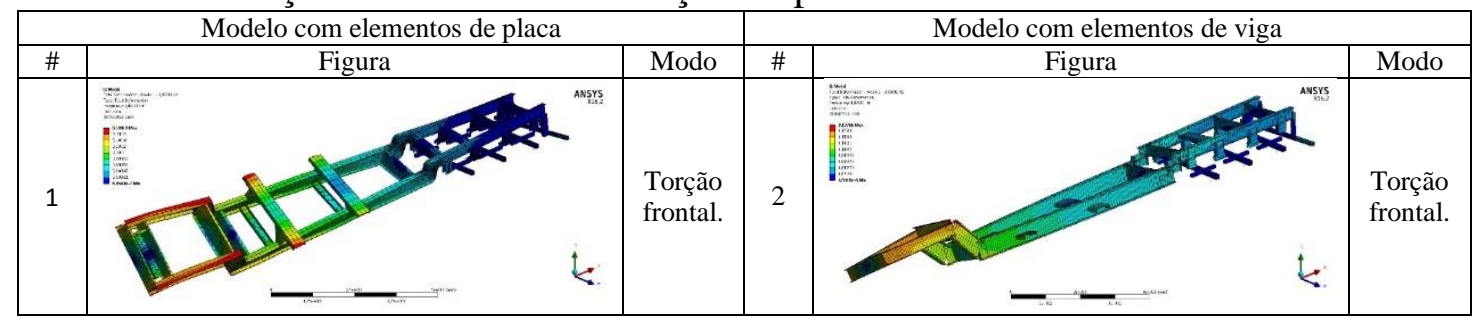




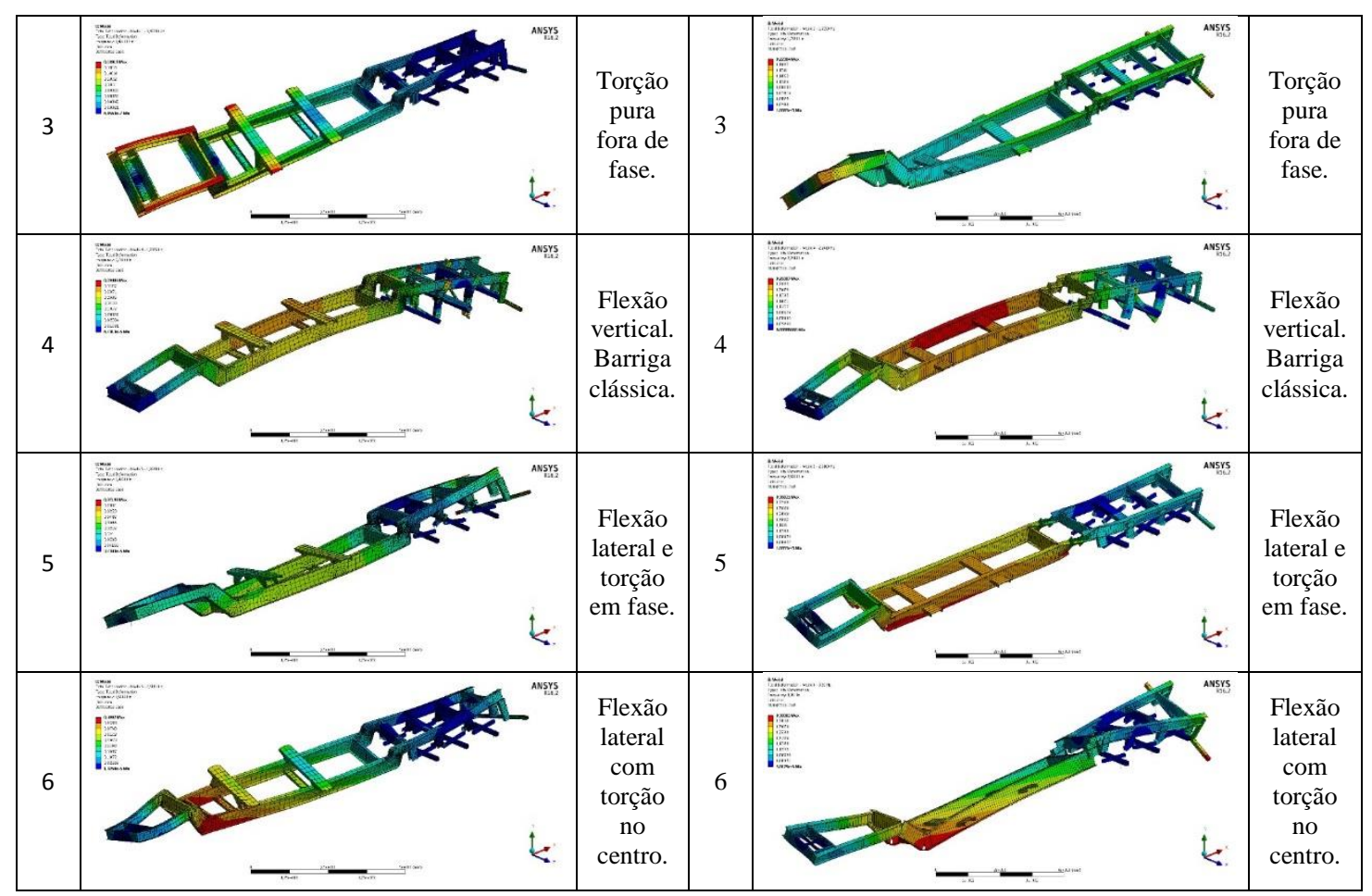

O primeiro modo de vibração do modelo com elementos de placa combina com o segundo modo de viga, ao contrário os modos 3, 4, 5 e 6 estão compatíveis entre si. Esperava-se uma relação menor por causa da complexibilidade da estrutura. No entanto, as relações encontradas são muito importantes, pois indicam os principais deslocamentos translacionais representando formas reais que a estrutura chassi vibra.

A comparação dos valores de frequências naturais entre EF do tipo placa e viga para o caso simples de uma viga em balanço pode ser analisada na Tabela 9.

Tabela 9 - Comparação das frequências naturais do primeiro modelo da estrutura chassi.

\begin{tabular}{|c|c|c|c|c|c|}
\hline Modo & Frequência (placa) & Modo & Frequência (viga) & Diferença & Erro \% \\
\hline 1 & $0,49 \mathrm{~Hz}$ & 2 & $0,83 \mathrm{~Hz}$ & $0,34 \mathrm{~Hz}$ & $40 \%$ \\
\hline 3 & $1,49 \mathrm{~Hz}$ & 3 & $1,76 \mathrm{~Hz}$ & $0,26 \mathrm{~Hz}$ & $15 \%$ \\
\hline 4 & $1,78 \mathrm{~Hz}$ & 4 & $2,24 \mathrm{~Hz}$ & $0,46 \mathrm{~Hz}$ & $21 \%$ \\
\hline 5 & $1,99 \mathrm{~Hz}$ & 5 & $2,51 \mathrm{~Hz}$ & $0,52 \mathrm{~Hz}$ & $21 \%$ \\
\hline 6 & $2,61 \mathrm{~Hz}$ & 6 & $3,35 \mathrm{~Hz}$ & $0,74 \mathrm{~Hz}$ & $22 \%$ \\
\hline
\end{tabular}

Sobre os erros visualizados acima, cita-se o primeiro como o mais discrepante, $0,34 \mathrm{~Hz}$ maior na estrutura chassi elementos de viga. Pode-se afirmar que a estrutura chassi está mais rígida com elementos de viga e o primeiro modo mostra o comportamento de torção frontal.

As pequenas diferenças são provenientes das diferenças de aproximações utilizadas na elaboração do modelo numérico. As próprias variações dimensionais da geometria entre um modelo e outro também contribuem para essas diferenças. 
Os valores do índice de MAC, Tabela 10, comprovam a relação entre os modos de vibração. O primeiro modelo da estrutura chassi tem 633 nós combinados de cada malha de EF.

Tabela 10 - Valores do índice de MAC do primeiro modelo da estrutura chassi.

\begin{tabular}{|c|c|c|c|c|c|c|c|c|c|c|c|}
\hline & \multicolumn{10}{|c|}{ Viga } \\
\hline & & 1 & 2 & 3 & 4 & 5 & 6 & 7 & 8 & 9 & 10 \\
\hline \multirow{10}{*}{ 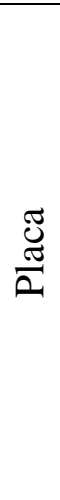 } & 1 & 0,38 & 0,93 & 0,18 & 0,03 & 0,10 & 0,04 & 0,15 & 0,01 & 0,00 & 0,01 \\
\hline & 2 & 0,10 & 0,10 & 0,57 & 0,01 & 0,17 & 0,05 & 0,24 & 0,00 & 0,00 & 0,17 \\
\hline & 3 & 0,20 & 0,10 & 0,72 & 0,00 & 0,29 & 0,28 & 0,03 & 0,00 & 0,01 & 0,04 \\
\hline & 4 & 0,09 & 0,05 & 0,01 & 0,96 & 0,01 & 0,02 & 0,01 & 0,00 & 0,08 & 0,00 \\
\hline & 5 & 0,52 & 0,25 & 0,00 & 0,00 & 0,81 & 0,04 & 0,00 & 0,00 & 0,00 & 0,25 \\
\hline & 6 & 0,46 & 0,01 & 0,01 & 0,05 & 0,46 & 0,94 & 0,09 & 0,00 & 0,00 & 0,41 \\
\hline & 7 & 0,01 & 0,01 & 0,07 & 0,05 & 0,14 & 0,00 & 0,00 & 0,05 & 0,08 & 0,15 \\
\hline & 8 & 0,04 & 0,00 & 0,04 & 0,05 & 0,04 & 0,02 & 0,30 & 0,03 & 0,00 & 0,15 \\
\hline & 9 & 0,12 & 0,02 & 0,01 & 0,01 & 0,14 & 0,06 & 0,23 & 0,14 & 0,03 & 0,02 \\
\hline & 10 & 0,00 & 0,00 & 0,01 & 0,06 & 0,01 & 0,00 & 0,01 & 0,90 & 0,61 & 0,33 \\
\hline
\end{tabular}

Até o sexto modo de vibração da estrutura chassi, o cálculo do índice de MAC indica 5 relações acima de 0,7. Combinação importante e valores razoáveis para o tipo da estrutura analisada. Tendo em conta a diferença da teoria de Timoshenko e MindlinReissner, os valores são excepcionalmente bons.

Para completar, a Figura 6 mostra a função Resposta em Frequência da comparação do primeiro modelo da estrutura do chassi do implemento rodoviário estudado.

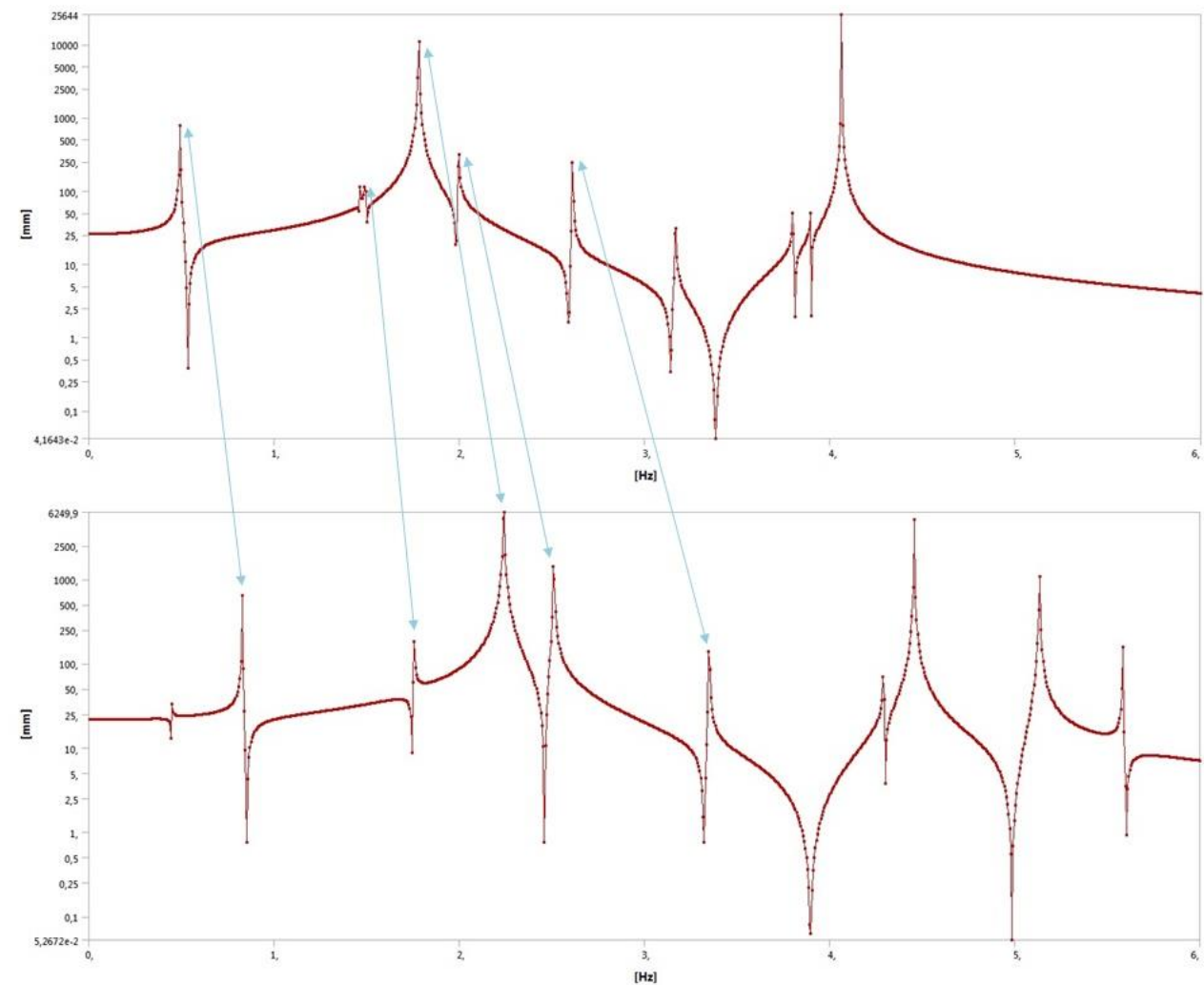

Figura 6 - Função Resposta em Frequência do primeiro modelo da estrutura chassi. 
Percebe-se vários picos alguns com amplitude maior e outros menores. Porém, as setas mostram os 5 modos de estudo do primeiro modelo ilustrando mesmo contorno quanto a vale e picos. Assim, a Função Resposta em Frequência prova frequências maiores com elementos de viga e a relação já mencionada.

Uma das desvantagens verificada nesse primeiro modelo da estrutura chassi é a mola fixada na base. O comportamento é diferente de um pneu, pois está fixado na base restringindo o deslocamento na vertical superior. Contudo, a mola é um elemento de suma importância e não deve ser desconsiderada em analises modais da estrutura chassi de implementos rodoviários, pois queremos analisar o chassi rodando. Os modos importantes se manifestam com a mola.

Seguindo as análises modais, o segundo modelo da estrutura chassi é simulado da mesma forma que o anterior. As relações dos modos de vibração são observados na Tabela 11.

Tabela 11 - Relação dos modos de vibração do segundo modelo da estrutura chassi.

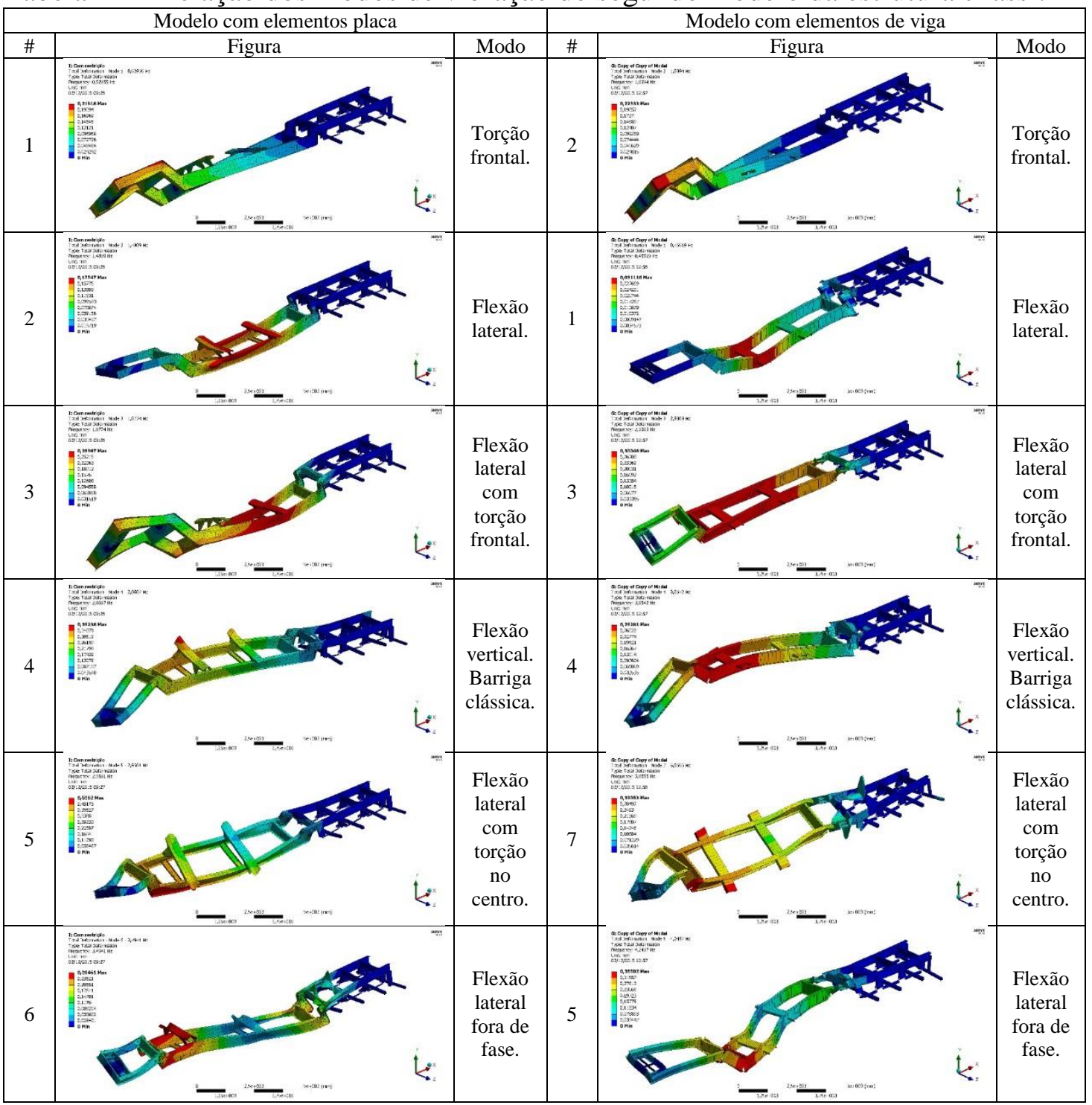


Verifica-se 6 modos relacionados com mesmo comportamento e deslocamentos similares. No modelo com viga alguns modos aparecem antes e outros depois como é o caso do primeiro modo do modelo de placa relacionado com o segundo modo de viga.

A comparação dos valores de frequências naturais entre placa e viga para esse modelo de EF pode ser visto na Tabela 12.

Tabela 12 - Comparação das frequências naturais do segundo modelo da estrutura chassi.

\begin{tabular}{|c|c|c|c|c|c|}
\hline Modo & Frequência (placa) & Modo & Frequência (viga) & Diferença & Erro \% \\
\hline 1 & $0,53 \mathrm{~Hz}$ & 2 & $1,04 \mathrm{~Hz}$ & $0,51 \mathrm{~Hz}$ & $49 \%$ \\
\hline 2 & $1,48 \mathrm{~Hz}$ & 1 & $0,46 \mathrm{~Hz}$ & $-1,03 \mathrm{~Hz}$ & $-225 \%$ \\
\hline 3 & $1,88 \mathrm{~Hz}$ & 3 & $2,34 \mathrm{~Hz}$ & $0,46 \mathrm{~Hz}$ & $20 \%$ \\
\hline 4 & $2,87 \mathrm{~Hz}$ & 4 & $3,85 \mathrm{~Hz}$ & $0,99 \mathrm{~Hz}$ & $26 \%$ \\
\hline 5 & $2,96 \mathrm{~Hz}$ & 7 & $5,06 \mathrm{~Hz}$ & $2,10 \mathrm{~Hz}$ & $41 \%$ \\
\hline 6 & $3,49 \mathrm{~Hz}$ & 5 & $4,24 \mathrm{~Hz}$ & $0,75 \mathrm{~Hz}$ & $18 \%$ \\
\hline
\end{tabular}

O erro do segundo modo de placa relacionado com o primeiro de viga é maior que os demais. Pela estrutura chassi ser mais rígida devido as condições de contorno no segundo modelo, encontra diferenças maiores comparado com o primeiro modelo da estrutura chassi.

Valores do índice de MAC estão mais desordenados comparando a Tabela 10 do primeiro modelo com a Tabela 13 do segundo modelo. Para os cálculos são combinados 633 nós da malha de placa e viga.

Tabela 13 - Valores do índice de MAC do segundo modelo da estrutura chassi.

\begin{tabular}{|c|c|c|c|c|c|c|c|c|c|c|c|}
\hline & \multicolumn{10}{|c|}{ Viga } \\
\hline & & 1 & 2 & 3 & 4 & 5 & 6 & 7 & 8 & 9 & 10 \\
\hline \multirow{10}{*}{$\frac{\tilde{\Xi}}{\tilde{\Xi}}$} & 1 & 0,01 & 0,96 & 0,14 & 0,00 & 0,05 & 0,00 & 0,06 & 0,01 & 0,12 & 0,01 \\
\hline & 2 & 0,79 & 0,00 & 0,84 & 0,00 & 0,27 & 0,17 & 0,61 & 0,52 & 0,05 & 0,00 \\
\hline & 3 & 0,31 & 0,34 & 0,86 & 0,00 & 0,02 & 0,05 & 0,43 & 0,27 & 0,16 & 0,00 \\
\hline & 4 & 0,07 & 0,00 & 0,12 & 0,90 & 0,01 & 0,36 & 0,07 & 0,08 & 0,04 & 0,19 \\
\hline & 5 & 0,47 & 0,00 & 0,54 & 0,08 & 0,62 & 0,57 & 0,85 & 0,82 & 0,04 & 0,01 \\
\hline & 6 & 0,34 & 0,01 & 0,23 & 0,04 & 0,76 & 0,32 & 0,29 & 0,30 & 0,30 & 0,01 \\
\hline & 7 & 0,25 & 0,00 & 0,25 & 0,08 & 0,48 & 0,02 & 0,20 & 0,38 & 0,39 & 0,03 \\
\hline & 8 & 0,02 & 0,02 & 0,01 & 0,01 & 0,07 & 0,08 & 0,00 & 0,01 & 0,01 & 0,72 \\
\hline & 9 & 0,00 & 0,01 & 0,00 & 0,69 & 0,28 & 0,62 & 0,00 & 0,01 & 0,07 & 0,21 \\
\hline & 10 & 0,08 & 0,13 & 0,00 & 0,09 & 0,00 & 0,12 & 0,12 & 0,07 & 0,60 & 0,00 \\
\hline
\end{tabular}

O ideal é obviamente uma matriz identidade. Entretanto, é possível ver alguns modos relacionados que apresentam-se destacados acima, mas apenas 2 modos estão combinados na diagonal da matriz.

Por último, a Figura 7 a Função Resposta em Frequência da comparação entre placa e viga do segundo modelo da estrutura chassi. 


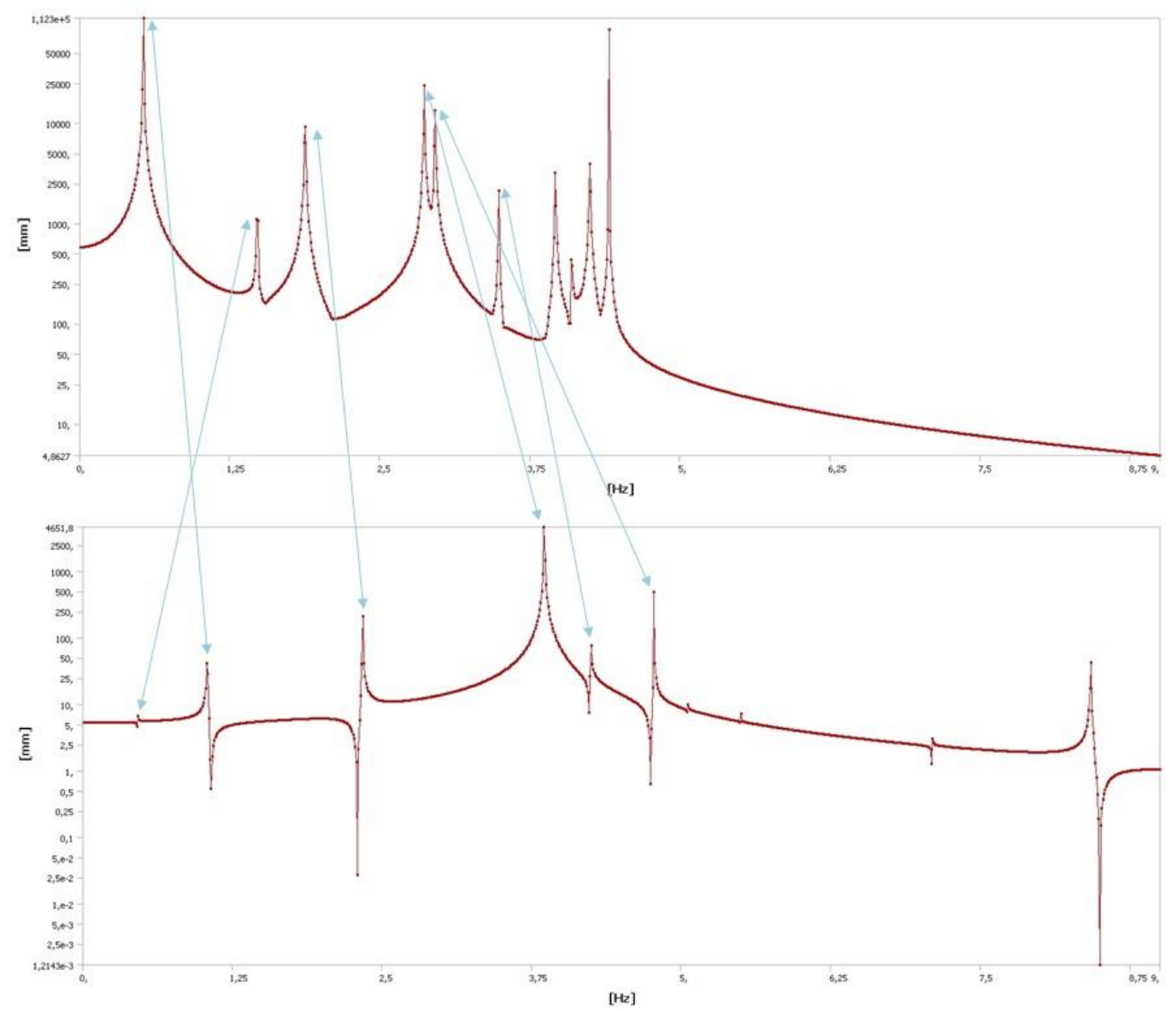

Figura 7 - Função Resposta em Frequência do segundo modelo da estrutura chassi.

Conforme esperado, nota-se vários cruzamentos das linhas que combinam os modos do modelo com placa e viga, vista superior e inferior, respectivamente.

A discrepância do segundo modelo removendo as molas que caracterizam os feixes de mola trapezoidal e pneus são maiores. A estrutura é mais rígida devido a essa condições de contorno dificultando a relação dos modos entre placa e viga.

Outra observação fundamental é perda do modo de torção pura fora de fase obtida no primeiro modelo da estrutura chassi. Além disso, estrutura mais rígida se desloca através de formas irreais que não contribuem a repostas dinâmica do sistema.

Outra condição de contorno analisada é a vibração livre da estrutura chassi com os corpos unidos. Salienta-se que é amplamente empregada para analises dinâmicas de implementos rodoviários.

Os resultados de relação dos modos de vibração do terceiro modelo para a faixa de frequência estudada tem apenas 3 relações. 
Tabela 14 - Relação dos modos de vibração do terceiro modelo da estrutura chassi.

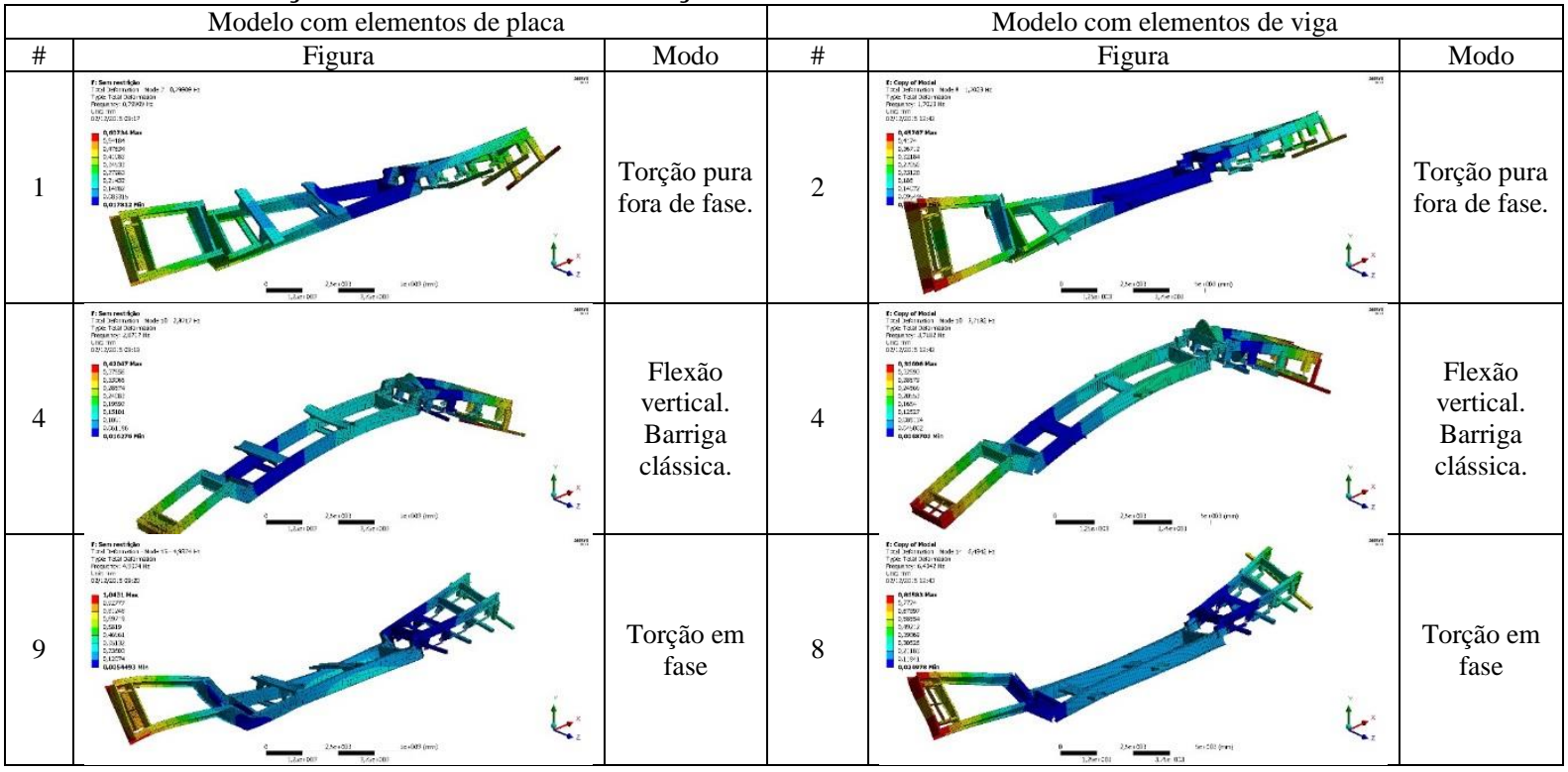

Duas combinações são clássicas, a primeira torção pura fora de fase e a segunda flexão vertical. No entanto, o primeiro modo de placa está relacionado com o segundo de viga. Evidentemente, apresenta um erro maior na comparação das frequências, Tabela 15.

Tabela 15 - Comparação das frequências naturais do terceiro modelo da estrutura chassi.

\begin{tabular}{|c|c|c|c|c|c|}
\hline Modo & Frequência (placa) & Modo & Frequência (viga) & Diferença & Erro \% \\
\hline 1 & $0,80 \mathrm{~Hz}$ & 2 & $1,70 \mathrm{~Hz}$ & $0,90 \mathrm{~Hz}$ & $53 \%$ \\
\hline 4 & $2,87 \mathrm{~Hz}$ & 4 & $3,72 \mathrm{~Hz}$ & $0,85 \mathrm{~Hz}$ & $23 \%$ \\
\hline 9 & $4,94 \mathrm{~Hz}$ & 8 & $6,43 \mathrm{~Hz}$ & $1,50 \mathrm{~Hz}$ & $23 \%$ \\
\hline
\end{tabular}

Para casos clássicos dos modos de vibração os erros de frequências naturais são classificados como grosseiros. A característica principal que se mantem entre os 3 modelos da estrutura chassi é a maior rigidez do modelo de viga da estrutura chassi.

O cálculo do índice de MAC reforça a forte relação entre os 3 modos combinados assim como mostra valores muito baixos da diagonal da matriz, Tabela 16. Conforme os demais modelos da estrutura chassi analisada, combina-se 633 nós da malha de placa e viga.

Tabela 16 - Valores do índice de MAC do terceiro modelo da estrutura chassi.

\begin{tabular}{|c|c|c|c|c|c|c|c|c|c|c|c|}
\hline & \multicolumn{10}{|c|}{ Viga } \\
\hline & & 1 & 2 & 3 & 4 & 5 & 6 & 7 & 8 & 9 & 10 \\
\hline \multirow{8}{*}{ 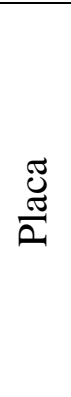 } & 1 & 0,03 & 0,96 & 0,26 & 0,00 & 0,05 & 0,36 & 0,11 & 0,00 & 0,04 & 0,00 \\
\hline & 2 & 0,66 & 0,39 & 0,04 & 0,00 & 0,02 & 0,23 & 0,05 & 0,04 & 0,04 & 0,00 \\
\hline & 3 & 0,00 & 0,11 & 0,48 & 0,01 & 0,02 & 0,20 & 0,07 & 0,00 & 0,00 & 0,02 \\
\hline & 4 & 0,00 & 0,01 & 0,00 & 0,99 & 0,05 & 0,04 & 0,61 & 0,00 & 0,00 & 0,03 \\
\hline & 5 & 0,07 & 0,02 & 0,27 & 0,08 & 0,30 & 0,12 & 0,08 & 0,06 & 0,18 & 0,04 \\
\hline & 6 & 0,09 & 0,02 & 0,04 & 0,01 & 0,60 & 0,04 & 0,00 & 0,26 & 0,11 & 0,00 \\
\hline & 7 & 0,01 & 0,00 & 0,01 & 0,13 & 0,14 & 0,23 & 0,02 & 0,02 & 0,50 & 0,01 \\
\hline & 8 & 0,00 & 0,02 & 0,01 & 0,42 & 0,03 & 0,17 & 0,64 & 0,03 & 0,40 & 0,02 \\
\hline
\end{tabular}




\begin{tabular}{|l|l|l|l|l|l|l|l|l|l|l|l|}
\hline & 9 & 0,05 & 0,11 & 0,07 & 0,00 & 0,38 & 0,26 & 0,03 & 0,91 & 0,01 & 0,01 \\
\hline & 10 & 0,00 & 0,00 & 0,00 & 0,14 & 0,03 & 0,03 & 0,01 & 0,12 & 0,01 & 0,11 \\
\hline
\end{tabular}

Verifica-se uma relação muito pobre entre os 6 primeiros modos, ou seja, apenas um valor acima de 0,5 do índice de MAC na diagonal.

Finalizando, a Figura 8 ilustra a Função Resposta em Frequência do terceiro modelo da estrutura do chassi.

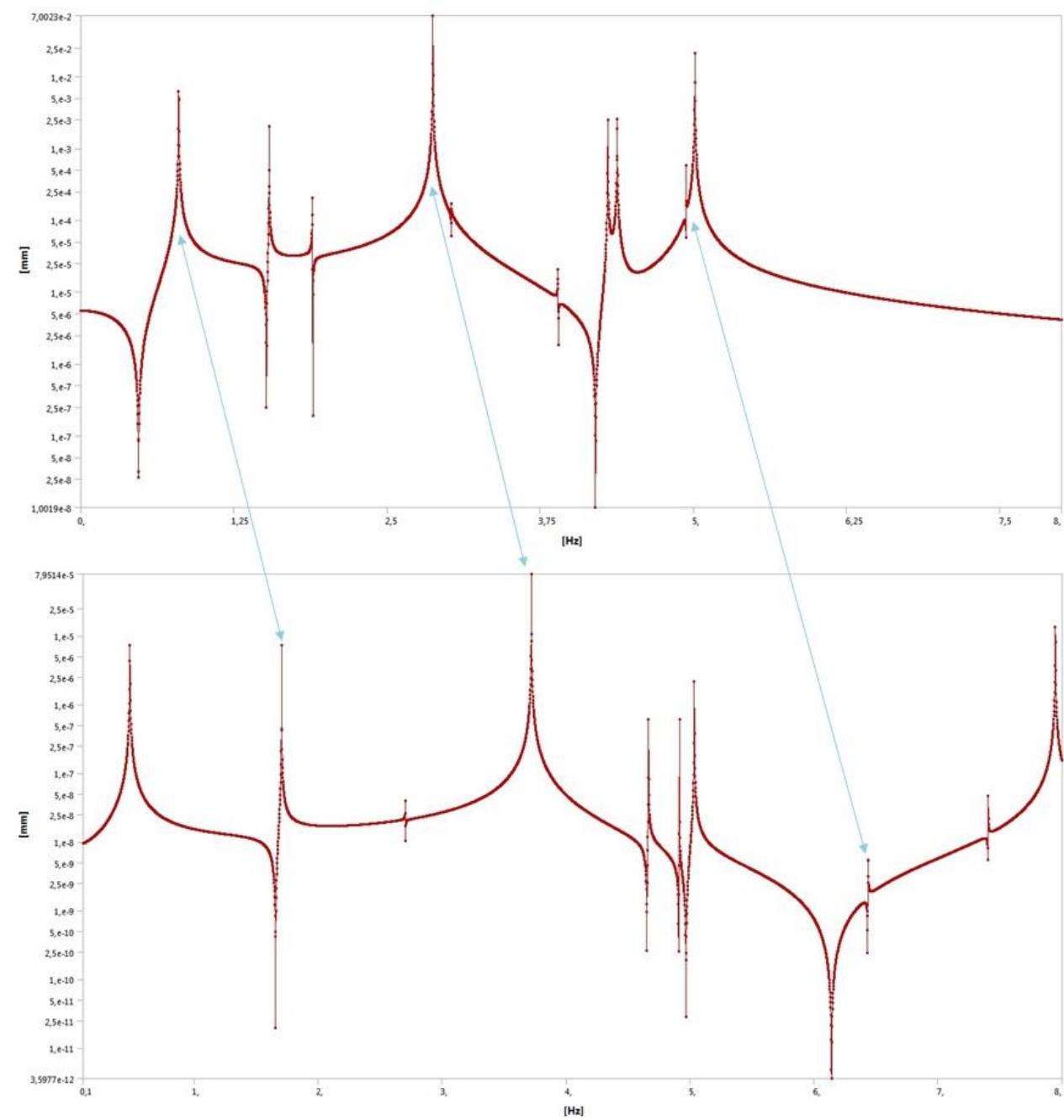

Figura 8 - Função Resposta em Frequência do terceiro modelo da estrutura chassi.

Analisando ambas os gráficos da Figura 8, conclui-se pouca convergência entre picos e frequências. As linhas estão inclinadas indicando os erros de frequências.

Outro detalhe é a falta do modo de torção frontal que é fundamental e não parece no terceiro modelo. A restrição nas rodas é importante para considerar esse modo de vibrar dinâmico. 


\section{CONCLUSÃO}

Modelos da teoria estrutural clássica, isto é, simples condições de contorno, geometria e carregamento, tanto para malha com elementos de placa quanto para malha com elementos de viga, possui a mesma concordância dos modos de vibração. $O$ caso simples de uma viga em balanço prova isso através da relação dos modos de vibração, Tabela 5, valores do índice de MAC, Tabela 7, e até mesmo Função Resposta em Frequência, Figura 5.

Já em casos mais complexos como implementos rodoviários é mais complicado alcançar a concordância dos modos. A matriz do índice de MAC começa a ficar desordenada, ou melhor, perde a diagonalização que é característica de modelos perfeitos.

Este trabalho aponta algumas práticas importantes que podem ser usadas para garantir a concordância dos modos:

- $\quad$ Obter as frequências naturais de vibração da estrutura chassi com suas devidas restrições e não a estrutura do implemento rodoviário livre;

- Optar por estruturas com condições de contorno mais flexíveis para não ocultar modos importantes;

- Utilizar a mola para permitir a flexão pura assimétrica;

Com isso, é possível fazer analises dinâmicas transientes de estruturas complexas com malhas simples que possuem quantidade viável de graus de liberdade, sem comprometer os resultados.

\section{REFERÊNCIAS}

[1] RANDALL, J. Allemang. The Modal Assurance Criterion - Twenty Years of Use and Abuse. Ohio: University of Cincinnati, 2003.

[2] ANSYS, Inc. Ansys Mechanical APDL Theory Reference. Canonsburg: SAS IP, Inc., 2015.

[3] GILLESPIE, T. D. Fundamentals of Vehicle Dynamics. Warrendale: SAE, 1992.

[4] VARGAS, V. A. Efeitos da Flexibilidade Estrutural em Simulações de Dinâmica Lateral de Veículo de Transporte de Carga. Porto Alegre: Universidade Federal do Rio Grande do Sul, 2011.

[5] BATHE, K. J. Finite Element Procedures. New Jersey: Prentice-Hall, 1996. 